\title{
Determination of Knowledge and Self Care Behavior of Heart Failure Pateints According to Orem Theory
}

\author{
Sabrin Mahmoud Fahim ${ }^{1}$, Mohamed Hosam El-Dein ${ }^{2}$, Hala Mohammed Ghanem ${ }^{3}$, Ghada Hassan Ahmed ${ }^{4}$. \\ 1. Nursing specialist at About-tig Central hospital, Faculty of Nursing, Assiut University, Assiut, Egypt. \\ 2. Professor, Internal medicine, Faculty of medicine, Assiut University, Assiut, Egypt. \\ 3. Assistant Professor, Adult Nursing Department, Faculty of Nursing, Assiut University, Assiut, Egypt. \\ 4. Lecturer, Adult Nursing Department, Faculty of Nursing, Assiut University, Assiut, Egypt.
}

\begin{abstract}
Background: Heart failure (HF) is a chronic disease that requires special lifelong self-care behaviors. These patients need having self-care behaviors to confront their disease problems. Aim of the study: To assess patient knowledge about heart failure and determine the self-care behavior of heart failure patients. Subject and methods: To conduct this study, a descriptive research design was utilized. Sample: a convenient sample of 60 patients with heart failure. The study was conducted in coronary care unit at Abou-tig central hospital. Tools: One tool was utilized to collect data for this study: Patient interviewing questionnaire sheet including three parts: Part (1) demographic characteristics of the patients, part (2): Dutch heart failure knowledge scale, part (3) Heart failure self-care behavior scale, Results: The majority of the studied patients $(75 \%)$ had unsatisfactory knowledge levels, while the minority (26.7\%) of them had good self-care behavior. Conclusion: The majority of the studied patients had unsatisfied level of knowledge about heart failure and had poor self-care behavior. Recommendation: patients with heart Failure are in pressing need for health education about their illness which will reflect on their self-care behavior and results in better quality of life
\end{abstract}

\section{Keywords: Heart Failure, Self-care Behavior \& Orem Theory.}

\section{Introduction}

Heart failure is a rapidly growing public health problem that affects at least 26 million people around the world. Despite significant advances in therapy and prevention, mortality and morbidity are still high (Savarese and Lund., (2017). By 2030, more than 8 million people in the United States (1 in every 33) will be affected by heart failure (Heidenreich et al., 2015). World health organization (WHO) reported that $23 \%$ of recorded deaths were certified to heart failure in Egypt in 2014 (WHO, 2014).

Heart failure is an abnormal clinical syndrome that includes inadequate pumping and/or filling of the heart, which is manifested by typical symptoms (e.g. Dyspnea, ankle swelling, and fatigue) and accompanied by signs (e.g. elevated jugular venous pressure, pulmonary crackles, and peripheral edema) that cause the heart to unable to provide enough blood oxygen to cover the demands of the tissues (Urden et al., 2019). To improve heart failure outcomes, in addition to pharmacological and medical management, guidelines highlight the importance of heart failure self-care in maintaining clinical stability (Lee et al., 2018).

Self-care has been defined as a realistic decision making process that involves two dimensions: Selfcare maintenance and self-care management. Selfcare maintenance consists of behaviors made by patients to sustain physiological stability of heart failure, monitoring of symptoms and adhering to treatment; self-care management includes behaviors directed at recognizing and interpreting symptoms of heart failure exacerbation, implementing treatments to relieve symptoms and evaluating implemented treatments (Cocchieri et al., 2015).

Heart failure Patients who report more effective selfcare have better quality of life, lower mortality and readmission rates than those who report poor selfcare. However, despite the clear relationship of effective self-care with positive health outcomes, many patients find it challenging to follow self-care guidance. This lack of adherence might be related to the complexity of self-care, lack of perceived need for self-care, the long-term character of the behavioral changes needed and a lack of motivation (Jaarsma et al., 2017).

Dorothea Orem (1914-2007): was a gentle, caring scholar whose life was dedicated to creation and development of a theoretical structure to improve nursing practice. The theory of self-care describes what a person requires and what actions need to be taken to meet those requirements. She defined selfcare in her self-care theory as the practice of activities that individuals initiate and perform on their own behalf to maintain life, health, and well-being. 
she added that a person's knowledge of potential health problems is necessary for promoting self-care behaviors (Taylor et al., 2006).

\section{Significance of the study}

Despite the importance of heart failure self-care on positive health outcomes, many patients with heart failure have inadequate self-care behaviors, and from the researcher,s clinical experience at Abou-tig central hospital; it has been observed that heart failure patients in coronary care unit had poor condition outcomes in addition to frequent re admission due to their poor self-care behavior. So this study will target those patients in attempt to determine their self -care behavior and knowledge level about heart failure.

\section{Aim of the study}

The aim of this study was two folds: to assess patient knowledge about heart failure and to determine the self-care behavior of heart failure patients.

\section{Research questions}

1. What is the knowledge level of heart failure patients about heart failure?

2. What is the self- care behavior level of heart failure patients in coronary care unit at Abou-tig central hospital?

\section{Subjects \& Method \\ Research design}

A descriptive research design was used to meet the aim of the study and the theoretical framework of this study is the self-care theory which developed by Dorothea Orem. The theory of self-care describes why and how people care for themselves. Self-care comprises the practice of activities that maturing and mature persons initiate and perform, within time frames, on their own behalf in the interest of maintaining life, healthful functioning, continuing personal development, and well-being by meeting known requisites for functional and developmental regulations (Orem, 2001).

Self-care activities among persons are internally and externally oriented actions. Internal activities involve knowledge and skills acquired to reach defined goals of self-care. It includes, among other things, having enough sleep and rest, eating a balanced diet, and exercising regularly. External activities are healthseeking behaviours from the environment. Seeking health advice from health professionals as to how to maintain health and prevent diseases is one of external self-care practices. As Orem stated, the purpose of self-care is to maintain health and wellbeing and promote development and disease prevention (Alligood, 2014).

\section{Setting}

The study was conducted in the coronary care unit at Abou -tig central Hospital, Abou -tig city - Assiut. Subjects

A convenient sample of 60 adult patients, male and female who admitted to coronary care unit and their age ranged from 18 to 65 year, collected from May to December 2017.The inclusion criteria: were defined as heart failure patient diagnosed by cardiologists based on signs and symptoms, chest radiography, ECG, and echocardiography, and agreed to participate in the study and able to communicate and answer the questions and diagnosed with heart failure more than 6 months.

\section{Tool of data collection}

Data pertinent to the study was collected using the following tool:

\section{Study tool was including the following}

Tool (I): Patient interviewing questionnaire sheet

This tool was conducted to assess patients' demographic data, knowledge about heart failure and self-care behavior of heart failure patients who admitted to coronary care unit. It was constructed and reviewed by using the most recent and relevant literature. It included three parts to cover the following

data:-

\section{Part 1: patient's demographic data}

It was developed by researcher using relevant literature to assess the necessary data about patients' demographic data. It included (7) items which cover the following; age, gender, educational level, and occupation, and medical data such as duration of heart failure and comorbid chronic diseases. Part II: Dutch heart failure knowledge scale (developed by Van der wal et al., 2005)

The aim of this part was to assess patients' knowledge about heart failure. The scale includes items regarding: a) heart failure general knowledge, b) heart failure symptoms, c) symptoms recognition, and d) management of heart failure including; low sodium diet, daily weight, fluid restriction, medication and exercise.

\section{Scoring system}

This scale was consists of 15 items multiple choices questions for each item, patients choose from three possible answers, one of which was the correct answer. Patients received one point for a correct answer and zero point for an incorrect or missing answer. The maximum score possible is 15 , which indicates that all items were answered correctly. Patients were classified as: having satisfactory level of knowledge at $60 \%$ or more of the range of total score or unsatisfactory level of knowledge at below $60 \%$. 
Part III: Heart failure self-care behavior scale (HFSBS) (developed by Ostergaard et al., 2017):

The aim of this part was to assess patient's self-care behavior about HF and measure its frequency as I weight myself every day, If my shortness of breath increases I contact my doctor or nurse, If my feet/legs become more swollen than usual I contact my doctor or nurse, If I gain $4 \mathrm{kegs}$ in one week I contact my doctor or nurse, I limit the amount of fluids I drink, If I experience increased fatigue I contact my doctor or nurse, I eat a low salt diet, I take my medications as prescribed and I exercise regularly.

\section{Scoring system}

The scale comprises 9 items including six levels for answers, Scores assigned to each item were between 1 and 5 points as follows; $0=$ none of the time, $1=\mathrm{A}$ little of the time, $2=$ some of the time, $3=\mathrm{A}$ Good bit of the time, $4=$ Most of the time and 5=All of the time. Patients were classified as: Having excellent behaviour at $75 \%$ or more of the range of total score or having good behaviour at $60 \%$ to less than $75 \%$ and lastly having poor behaviour at below $60 \%$.

Methods of data collection

- A review of national and international related literature in the various aspects of the problem using books, articles, periodicals, and magazines was done.

- Tool validity and reliability were assured.

- An official letter was issued from the Dean of the Faculty of Nursing to the head of authorized administration in Abou-tig central hospital soliciting the necessary approval to conduct the present research after explaining the aim and nature of the study to them to obtain their cooperation.

- At initial interview; the researcher introduced herself to initiate communication and explained the nature and purpose of the study.

- The researcher interviewed with each patient individually to fill out the study tool.

- The researcher assessed the patient's knowledge and self-care behavior by using the study tool that was previously mentioned.

- The study was carried out at morning and afternoon shifts every day.

- The questionnaire sheet was entered into computer for data analysis by utilizing SPSS program.

\section{Tool validity}

Tool's validity was tested through a jury of (5) experts $(3$ specialists in the field of medical - surgical nursing and 2 specialists in the field of cardiology medicine) from Assiut University; their opinions were formulated as regards to the tool format layout, applicability, clarity, relevance and understanding. The needed modifications were done accordingly.

\section{Pilot study}

A pilot study was carried out in July 2017 to evaluate the clarity and applicability of the study tool. It was conducted on $10 \%$ of the sample in the selected setting, it consisted of (6) patients who were added to the study later as there were no modifications.

\section{Ethical considerations}

- Research proposal was approved from Ethical Committee in the Faculty of Nursing.

- There was no risk for the study subjects during application of the research.

- The study followed common ethical principles in clinical research.

- Oral consent was obtained from patients who participated in the study, after explaining the nature and purpose of the study.

- Confidentiality and anonymity were assured.

- Study subjects had the right to refuse to participate and or withdraw from the study without any rational any time.

- Study subject privacy was considered during collection of data.

\section{Statistical analysis}

The statistical Package for (SPSS) version (23) was used to analyze data. Descriptive statistics was used for the quantitative data in knowledge and self-care behavior questionnaire and the demographic data. Descriptive statistics included: Frequencies, percentages and cross tabulation. The level of significance for this study was set at $(p<0.05)$ to detect any indication of differences found in the data available. 


\section{Results}

Table (1): Distribution of demographic characteristics of the studied patients $(n=60)$.

\begin{tabular}{|l|c|c|}
\hline \multicolumn{1}{|c|}{ characteristics } & No \\
\hline Age group & 1 & 1.7 \\
\hline $18 \geq 35$ & 5 & 8.3 \\
\hline $35>50$ & 54 & 90.0 \\
\hline $50 \geq 65$ & \multicolumn{2}{|c|}{} \\
\hline Mean \pm SD $55.73 \pm 5.6$ & 31 & 51.6 \\
\hline Gender & 29 & 48.4 \\
\hline Male & \multicolumn{2}{|c|}{} \\
\hline Female & 47 & 78.3 \\
\hline Level of education & 4 & 6.7 \\
\hline Non-educated & 5 & 8.3 \\
\hline read and write & 3 & 5.0 \\
\hline less than high school & 1 & 1.7 \\
\hline college degree & \multicolumn{2}{|c|}{} \\
\hline master's degree & 25 & 41.7 \\
\hline Occupation & 4 & 6.7 \\
\hline Farmer & 29 & 48.3 \\
\hline Employee & 2 & 3.3 \\
\hline house wife & 60 & $100 \%$ \\
\hline Others & \multicolumn{2}{|c|}{} \\
\hline Total & \multicolumn{2}{|c|}{} \\
\hline
\end{tabular}

Table (2): Distribution of the studied patients regarding to their medical data $(n=60)$

\begin{tabular}{|c|c|c|}
\hline Medical data & NO & $\%$ \\
\hline \multicolumn{3}{|l|}{ comorbidities } \\
\hline Hypertention & 25 & 41.6 \\
\hline kidney failure & 2 & 3.3 \\
\hline Diabetes mellitus & 16 & 11.7 \\
\hline Lung disease & 1 & 1.7 \\
\hline Stroke & 1 & 1.7 \\
\hline Non & 15 & 25 \\
\hline \multicolumn{3}{|l|}{ Duration of heart failure } \\
\hline 6 month-1 year & 7 & 11.7 \\
\hline $1-2$ year & 18 & 30.0 \\
\hline 3-5 year & 14 & 23.3 \\
\hline 5-7 year & 7 & 11.7 \\
\hline $7-10$ year & 3 & 5.0 \\
\hline more than 10 year & 11 & 18.3 \\
\hline
\end{tabular}




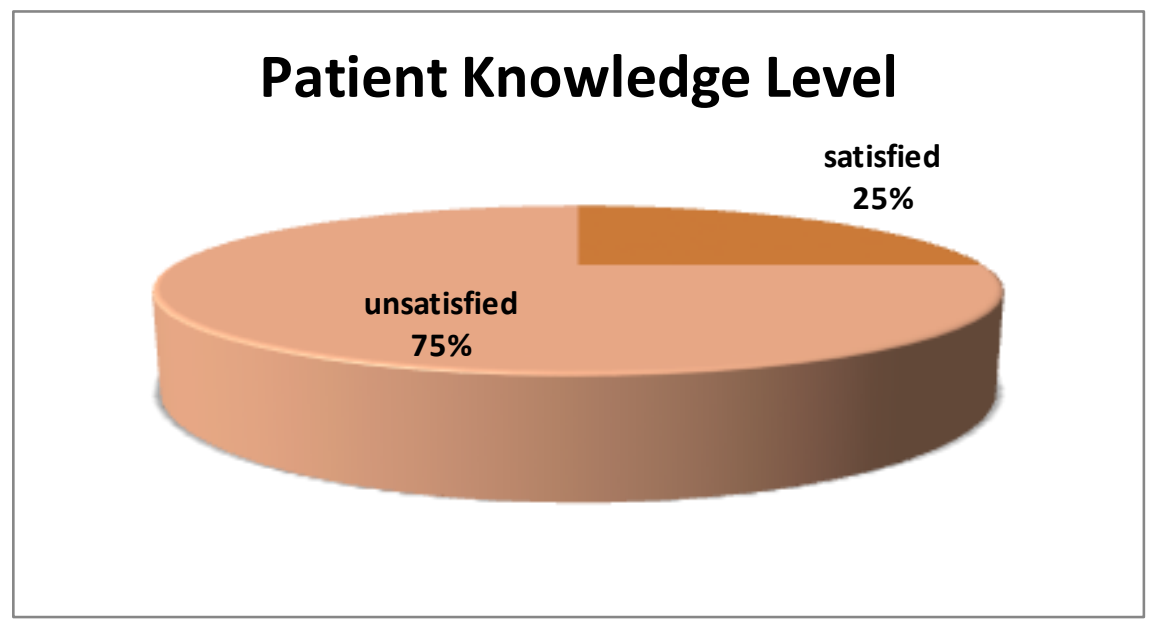

Fig (1): Distribution of the studied patients regarding their level of knowledge about heart failure $(n=60)$

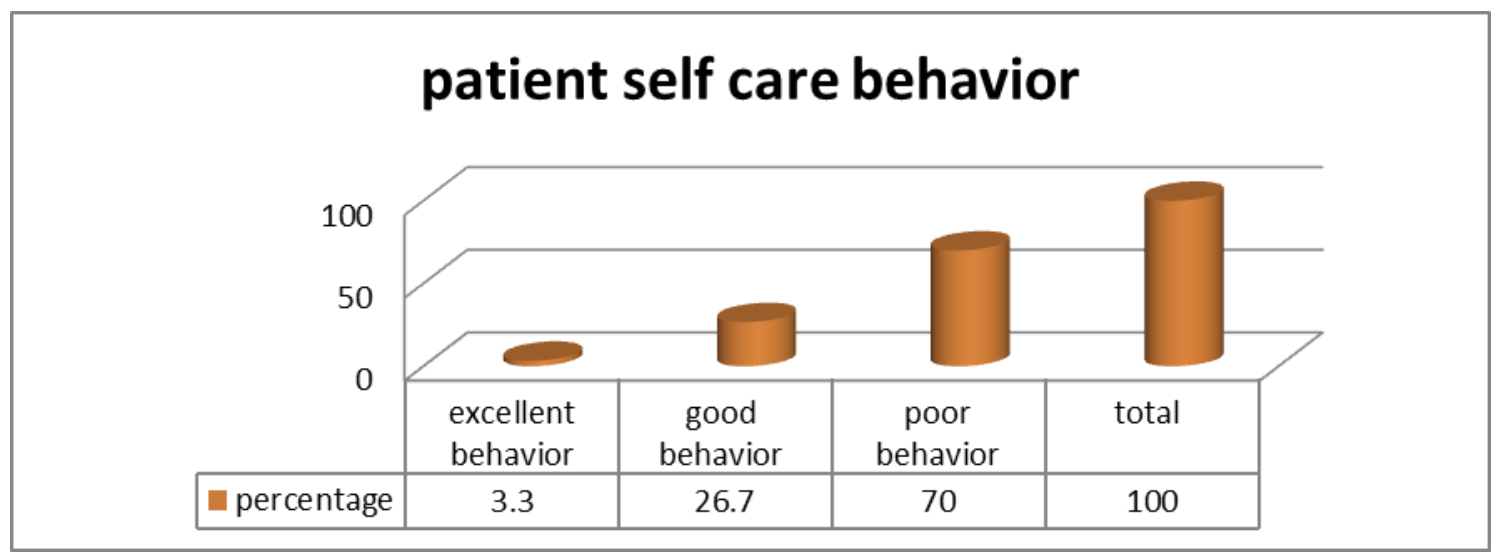

Fig (2): Percentage distribution of studied patients regarding their self-care behavior

Table (3): Relation between demographic characteristics and patients self-care behavior (no=60)

\begin{tabular}{|c|c|c|c|c|c|c|c|c|}
\hline \multirow[t]{2}{*}{ Variables } & \multicolumn{2}{|c|}{$\begin{array}{l}\text { Excellent } \\
\text { behavior }\end{array}$} & \multicolumn{2}{|c|}{$\begin{array}{c}\text { Good } \\
\text { behavior }\end{array}$} & \multicolumn{2}{|c|}{$\begin{array}{c}\text { Poor } \\
\text { Behavior }\end{array}$} & \multirow{2}{*}{$\begin{array}{c}\text { Total } \\
60\end{array}$} & \multirow[t]{2}{*}{ p.val. } \\
\hline & $\mathbf{N}$ & $\%$ & $\mathbf{N}$ & $\%$ & $\mathbf{N}$ & $\%$ & & \\
\hline \multicolumn{9}{|l|}{ Age group } \\
\hline $18 \geq 35$ & 0 & 0 & 0 & 0 & 1 & $1.7 \%$ & $1(1.7 \%)$ & \multirow{3}{*}{$0.93^{\mathrm{NS}}$} \\
\hline $35>50$ & 0 & 0 & 1 & $1.7 \%$ & 4 & $6.7 \%$ & $5(8.3 \%)$ & \\
\hline $50 \geq 65$ & 2 & $3.3 \%$ & 15 & $25.0 \%$ & 37 & $61.7 \%$ & $54(90.0 \%)$ & \\
\hline \multicolumn{9}{|l|}{ Gender } \\
\hline Male & 2 & $3.3 \%$ & 13 & $21.7 \%$ & 16 & $26.7 \%$ & $31(51.7 \%)$ & \multirow{2}{*}{$0.005^{* *}$} \\
\hline Female & 0 & 0 & 3 & $5 \%$ & 26 & $43.3 \%$ & $29(48.3 \%)$ & \\
\hline \multicolumn{9}{|l|}{ Level of education } \\
\hline Non educated & 1 & $1.7 \%$ & 11 & $18.3 \%$ & 35 & $58.3 \%$ & $47(78.3 \%)$ & \multirow{5}{*}{$0.017^{*}$} \\
\hline Read and write & 1 & $1.7 \%$ & 0 & 0 & 3 & $5.0 \%$ & $4(6.7 \%)$ & \\
\hline Less than high school & 0 & 0 & 1 & $1.7 \%$ & 4 & $6.7 \%$ & $5(8.3 \%)$ & \\
\hline College degree & 0 & 0 & 3 & $5.0 \%$ & 0 & 0 & $3(5.0 \%)$ & \\
\hline Master's degree & 0 & 0 & 1 & $1.7 \%$ & 0 & 0 & $1(1.7 \%)$ & \\
\hline
\end{tabular}




\begin{tabular}{|c|c|c|c|c|c|c|c|c|}
\hline \multirow[t]{2}{*}{ Variables } & \multicolumn{2}{|c|}{$\begin{array}{l}\text { Excellent } \\
\text { behavior }\end{array}$} & \multicolumn{2}{|c|}{$\begin{array}{c}\text { Good } \\
\text { behavior }\end{array}$} & \multicolumn{2}{|c|}{$\begin{array}{c}\text { Poor } \\
\text { Behavior }\end{array}$} & \multirow{2}{*}{$\begin{array}{c}\text { Total } \\
60\end{array}$} & \multirow[t]{2}{*}{ p.val. } \\
\hline & $\mathbf{N}$ & $\%$ & $\mathbf{N}$ & $\%$ & $\mathbf{N}$ & $\%$ & & \\
\hline \multicolumn{9}{|l|}{ Occupation } \\
\hline Farmer & 2 & $3.3 \%$ & 9 & $15.0 \%$ & 14 & $23.3 \%$ & $25(41.7 \%)$ & \multirow{4}{*}{$0.18^{\mathrm{NS}}$} \\
\hline Employee & 0 & 0 & 2 & $3.3 \%$ & 2 & $3.3 \%$ & $4(6.7 \%)$ & \\
\hline House wife & 0 & 0 & 4 & $6.7 \%$ & 25 & $41.7 \%$ & $29(48.3 \%)$ & \\
\hline Others & 0 & 0 & 1 & $1.7 \%$ & 1 & $1.7 \%$ & $2(3.3 \%)$ & \\
\hline Total & 2 & $3.3 \%$ & 16 & $26.7 \%$ & 42 & $70.0 \%$ & $60(100 \%)$ & \\
\hline
\end{tabular}

Table (4): Relation between patient's heart failure knowledge and their self -care behavior $(n=60)$.

\begin{tabular}{|l|c|c|c|c|c|c|c|c|}
\hline \multirow{2}{*}{ Characteristics } & \multicolumn{2}{|c|}{$\begin{array}{c}\text { Excellent } \\
\text { behavior }\end{array}$} & \multicolumn{2}{|c|}{$\begin{array}{c}\text { Good } \\
\text { behavior }\end{array}$} & \multicolumn{2}{|c|}{$\begin{array}{c}\text { Poor } \\
\text { behavior }\end{array}$} & \multirow{2}{*}{$\begin{array}{c}\text { Total } \\
\text { 60 }\end{array}$} & \multirow{2}{*}{ P. value } \\
\cline { 2 - 8 } & $\mathbf{N}$ & $\%$ & $\mathrm{~N}$ & $\%$ & $\mathrm{~N}$ & $\%$ & & \\
\hline Good knowledge & 0 & 0 & 6 & $10.0 \%$ & 9 & $15.0 \%$ & $15(25.0 \%)$ & 0.13 \\
Poor knowledge & 2 & $3.3 \%$ & 10 & $16.7 \%$ & 33 & $55.0 \%$ & $45(75.0 \%)$ & \\
\hline Total & 2 & $3.3 \%$ & 16 & $26.7 \%$ & 42 & $70.0 \%$ & $60(100 \%)$ & \\
\hline
\end{tabular}

$N s=$ Non significant difference $P$ value $>0.05$, use Pearson chi-square (cross tabs test).

Table (1): Shows that the majority of the studied patients $(90 \%)$ their age ranged from $(50 \geq 65)$ years, non educated, more than half $(51.6 \%)$ of them were males and as regards to occupation less than half $(48.3 \%)$ of studied patients were house wives and approximately two fifths $(41.7 \%)$ of them were farmers.

Table (2): Reveals that approximately two fifths (41.6\%) of studied patients were hypertensive and regarding the duration of heart failure, it illusterates that less than one third $(30 \%)$ of them had heart failure within the duration of one to two years.

Fig (1): Shows that the majority of patients $(75 \%)$ had unsatisfactory knowledge level.

Fig (2): Shows that the majority of the studied patients (70\%) had poor self-care behavior.

Table (3): Shows highly statistical significant difference between gender and patients self-care behavior with ( $\mathrm{P}$ value 0.005$)$, and there was a statistical significant diffirence between level of education and self-care behavior with ( $\mathrm{p}$ value 0.017), while there was no statistical diffirence between self- care behavior and age group or occupation.

Table (4): Shows that; there was no statistical difference between patients's heart failure knowledge and their self-care behavior.

\section{Discussion}

Self-care considers a corner stone of heart failure management, as people with adequate self-care have better quality of life and fewer hospitalizations. So this study was conducted to assess patients' knowledge about heart failure and to determine selfcare behavior of heart failure patients.

Patients' demographic characteristics

In our study, findings regarding patient characteristics revealed that heart failure is more common in patients who aged between $(50 \geq 65)$ than other younger age groups, this finding is in agreement with Hinkle \& Cheever, (2014) who reported that the incidence of heart failure increases with age .Regarding gender, more than half of the studied sample were men, this result supported by Gomez-Soto, et al., (2011) who stated that this syndrome affects men more than women.

Concerning their educational level, our results demonstrate that the majority of the studied sample were non educated, this result comes in agreement with Baker et al., (2011) who found the same result. that's may be attributes that all patients live in rural area and the majority of them were old age where education was not very common like now a days.

This study show that the most common comorbidity disease among study sample was hypertension, this result was in agreement with Roger et al., (2011) who stated that $75 \%$ of heart failure patients had hypertension as a risk factor for heart failure.

Patients' knowledge about heart failure

Based on the results of the present study, the majority of the studied sample had poor level of knowledge about heart failure; this result is in the same line with 
Lainscak \& Keber., (2010) who found that more than fifty percent of patients had unsatisfactory level of knowledge about heart failure.The poor Knowledge level of the study sample may be due to the high letracy percent of the studied patients which considers a barrier to access to knowledge about heart failure.

Patients' self-care behavior regarding heart failure

In our study, findings demonstrate that, the majority of heart failure patients $(70 \%)$ had poor self-care behavior. That isn't surprising; as a study conducted in Italy by Cocchieri et al., (2014) reported that the majority of heart failure patients had poor self-care behavior. This may be due to known barriers to selfcare, such as poor knowledge about heart failure selfcare, lack of social support, depression, and anxiety, combined with the complexity of self-care, in addition, patients tend to find self-care maintenance behaviors (i.e. such as taking medications or attending medical visits) easier than self-care management behaviors (i.e. symptom response behaviors) .

The current study demonstrated that there is a statistical significant relation between self-care behavior and gender; that findings showed that heart failure male patients had better adherence to self-care behavior than female ones. This result is consistent with Dickson, (2011) who indicated that men have better self-care behavior than women, This may be explained by That; Women can play a good role as a care -giver rather than care- taker, additionally, women consider a corner stone of their families which increase their resbonsibilities and limit their ability to adhere to self-care behaviors. instead, Cameron, (2010) found that being male puts $\mathrm{HF}$ patients at higher risk for poor self-care behavior.

Regarding the relation between self-care behavior and education, the present study revealed that there is a statistical significant relation between self-care behavior and education; as the better educated patient, the better hislher self-care behavior. This result is in agreement with Abootalebi (2012) who found the same result. One explaination is that the patients with higher education level have higher level of reasoning and decision making for conducting self-care behavior and they can simply gain knowledge about the management of their disease, conversely Dunlay, (2011) reported that there is no significant relation between patient's self-care behavior and their level of education.

Relation between patients' heart failure knowledge and their self-care behavior

Lastly, the current study shows that there is no statistical difference between patients' heart failure knowledge and their self-care behavior. This result is in accordance with Matsuoka et al., (2016) who reported that health literacy is independently associated with self-care behavior. In this respect, Jaarsma et al., (2017) added that knowledge is necessary, but insufficient to change self-care behavior .In addition to acquiring knowledge, there are several factors that may affect self-care behavior such as experience and skills, motivation, habits, cultural beliefs and values, functional abilities and cognitive abilities, confidence, support and access to care.

\section{Conclusion}

Based on the findings of the current study, it can be concluded that: the majority of heart failure patients had an unsatisfied level of knowledge about heart failure. In addition, they had poor heart failure selfcare behavior.

\section{Recommendations}

Based on the findings of the present study, the following recommendations were suggested:

1. More effort needs to be devoted to understanding heart failure self-care prior to interventionsBasic knowledge of heart failure and self-care could be raised and reinforced and symptoms monitored using social media via cell phone to provide ongoing reminders about key aspects of heart failure self-care.

2. Development of self-care program with a companion teaching booklet and video-tape that can be helpful for patients and their care givers.

\section{For further research}

1. Replication of the study on a large probability sample acquired from different geographical areas in Egypt to figure out the main aspects of this problem.

2. Studies are needed to identify factors affecting self-care behavior to investigate methods of improving self-care.

3. Research on clinical assessment of self-care, mitigation of potential barriers to achieving sufficient self-care experience and expertise, and refinement of interventions to improve self-care are needed to improve heart failure outcomes.

\section{References}

1. Abootalbi G., Nejad N., Namadi M., and Kaji M., (2012): Study of the self care in patients with heart failure, Iran J Crit Care Nurs, vol.4, Pp.203208.

2. Baker, D., Asch, S., Keesey, J., Brown, J., Chan, K., \& Joyce, G., (2011): difference in education, knowledge, self- management 
activities, and health outcomes for patients with heart failure cared for under the chronic disease model: the improving chronic illness care evaluation, J Card Fail, vol.11, No.6, Pp.405-413.

3. Cameron J., Worrall-Carter L., Page K., (2010): Self-care behaviours and heart failure: Does experience with symptoms really make a difference?, Eur J Cardiovasc Nurs, vol. 9, Pp. 92-100

4. Cocchieri, A., Riegel, B., Agostino, F., Rocco, G., Fida, R., Alvaro, R., \& Vellone, E., (2015): Describing self-care in Italian adults with heart failure and identifying determinants of poor selfcare, Eur J Cardiovasc Nurs, vol. 14, No.2, Pp.126-136.

5. Cocchieri, A., Riegel, B., D'Agostino, F., Rocco, G., Fida, R., Alvaro, R., \& Vellone, E., (2014): Describing self-care in adults with heart failure and identifying determinants of poor self-care, Eur J Cardiovasc Nurs, vol. 10, Pp.145-149.

6. Dickson V., Worrall-Carter L., Kuhn L., \& Riegel B., (2011): Whose job is it? Gender differences in perceived role in heart failure, self-care, J Nurs Health Care Chron Illn, vol. 3, Pp. 99-108.

7. Dunlay S., Weston S., Jacobsen S., \& Roger V., (2011): Risk factors for heart failure: a population - based case- control study, Am J Med, vol.122, Pp.1023-1028.

8. Gomez-Soto, F., Andrey, J., Garcia-Egido, A., Escobar, M. A., Romero, S. P., Garcia-Arjona, R., \& Gomez, F., (2011): Incidence and mortality of heart failure: a community-based study, Inter $\mathbf{J}$ cardiol, vol. 151, No.1, Pp. 40-45.

9. Heidenreich, P., Albert, N., \& Allen, L., (2015): Forecasting the impact of heart failure in the United States: a policy statement from the American heart association, circulation Heart Fail, vol.12, No 3, Pp.606-619.

10. Hinkle, J., \& Cheever, K., (2014): Brunner \&Suddartgs textbook of medical surgical nursing, $13^{\text {th }}$ ed, ch 25 , assessment of cardiovascular function,wolters kluwer health, lipppincott williams \& wilkins, Pp.1400-1404

11. Jaarsma, T., Cameron, J., Riegel, B., \& Stromberg, A., (2017): Factors Related to SelfCare in Heart Failure Patients According to the Middle-Range Theory of Self-Care of Chronic Illness: a Literature Update, J Curr Heart Fail Rep, vol.14, Pp.71-77.

12. Lainscak, M., \& Keber, I., (2010): validation of self- assessment: patient Knowledge questionnaire for heart failure patients, Eur $\mathbf{J}$ Cardiovasc Nurs, vol.6, Pp.105-155.
13. Lee, C., Bidwell, J., Paturzo, M., Alvaro, R., Cocchieri, A., Jaarsma, T., Strömberg, A., Riegel, B., \& Vellone, A., (2018): Patterns of self-care and clinical events in a cohort of adults with heart failure: 1 year follow-up, Heart \& Lung, vol.47, Pp.40-46.

14. Alligood, M., (2014): Nursing theorists and their work, $8^{\text {th }}$ ed, ch 14 , Dorotheo E. Orem, Elsevier, Pp. 246.

15. Matsuoka, S., Tsuchihashi-Makaya, M., Kayane, T., Yamada, M., Wakabayashi, R., \& Kato, N., (2016): Health literacy is independently associated with self-care behavior in patients with heart failure, Patient Educ Couns, vol.99, No.10, Pp.26-32.

16. Orem, D., (2001): Nursing: Concepts of practice, $6^{\text {th }}$ ed, St. Louis: Mosby, Pp. 522.

17. Østergaard, B., Mahrer-Imhof, R., Lauridsen, J., \& Wagner, L., (2017): Validity and reliability of the Danish version of the 9-item European Heart Failure Self-care Behavior Scale, Scandinavian journal of caring sciences, vol. 31, No.2, Pp. 405-412.

18. Roger V., Go A., Lioyd-Jones D., Adams R., Berry J., \& Brown T., (2011): Heart disease and stroke statistics-2011 Update: a report from the American Heart Association.

19. Savarese, G., \& Lund, L., (2017): Global Public Health Burden of Heart Failure, Card Fail Rev, vol. 3, No. 1, Pp. 7-11.

20. Taylor, S., Compton, A., Eben, J., Emerson, S., Gashti, N., Tomey, A., \& Nordmeyer, S., (2006): Dorothea E. Orem: Self-care deficit theory of nursing. Nursing theorists and their work, Elsevier, Pp. 267-296.

21. Urden, L., Stacy, K., \& Lough, M., (2019): Cardiovascular alterations, ch11, Priorities in critical care nursing, $8^{\text {th }}$ ed , Elsevier, Pp.146-186.

22. Van Der Wal, M., Jaarsma, T., Moser, D., \& Van veldhuisen, D., (2005): Development and testing of the Dutch heart failure knowledge scale, Eur J Cardiovasc, vol.4, No.4, Pp.273-277.

23. World health organization, (2014): WHO mortality database, 2014 edition. 